\title{
Correction to: Durability study of asphaltene-reinforced HDPE and LDPE composites under UV irradiation and local weathering exposure
}

Mohammad Nahid Siddiqui ${ }^{1}$ (D) Halim H. Redhwi ${ }^{2} \cdot$ Muhammad Younas $^{3}$. Abdulrahman A. Al-Arfaj ${ }^{1} \cdot$ Syed Hussain ${ }^{4} \cdot$ Mohd Naim $^{1}$

Published online: 17 August 2020

(c) Springer-Verlag GmbH Germany, part of Springer Nature 2020

\section{Correction to: Polymer Bulletin https://doi.org/10.1007/s00289-020-03326-w}

Unfortunately, the original version of this article contained a typo error in Figs. 2 and 3. Correct Figs. 2 and 3 are given below.

The original article can be found online at https://doi.org/10.1007/s00289-020-03326-w.

Mohammad Nahid Siddiqui

mnahid@kfupm.edu.sa

1 Chemistry Department, King Fahd University of Petroleum and Minerals, Dhahran 31261, Saudi Arabia

2 Chemical Engineering, King Fahd University of Petroleum and Minerals, Dhahran 31261, Saudi Arabia

3 Mechanical Engineering, King Fahd University of Petroleum and Minerals, Dhahran 31261, Saudi Arabia

4 Dhahran Techno Valley, King Fahd University of Petroleum and Minerals, Dhahran 31261, Saudi Arabia 

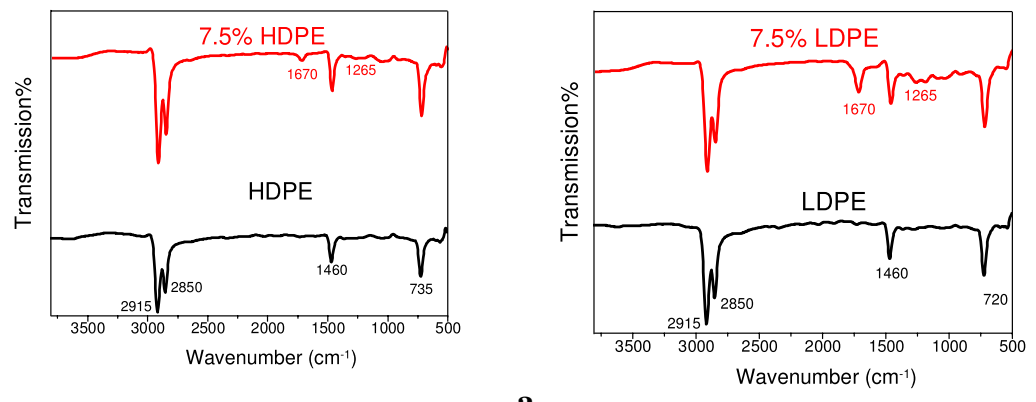

a
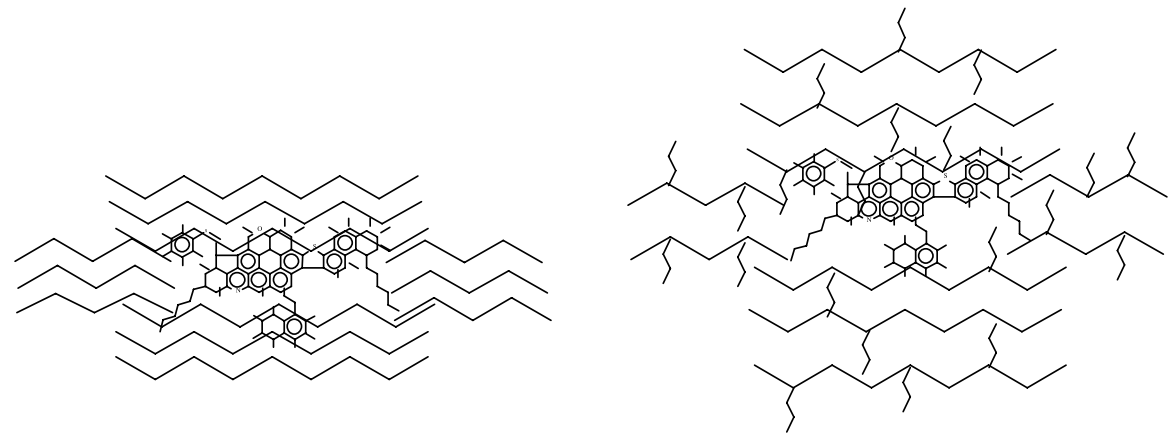

HDPE-Asphaltene composite

b

LDPE-Asphaltene composite

Fig. 2 a FTIR spectra of HDPE/LPDE polymers-asphaltene composites. b A schematic diagram of HDPE/LPDE polymers-asphaltene composites 

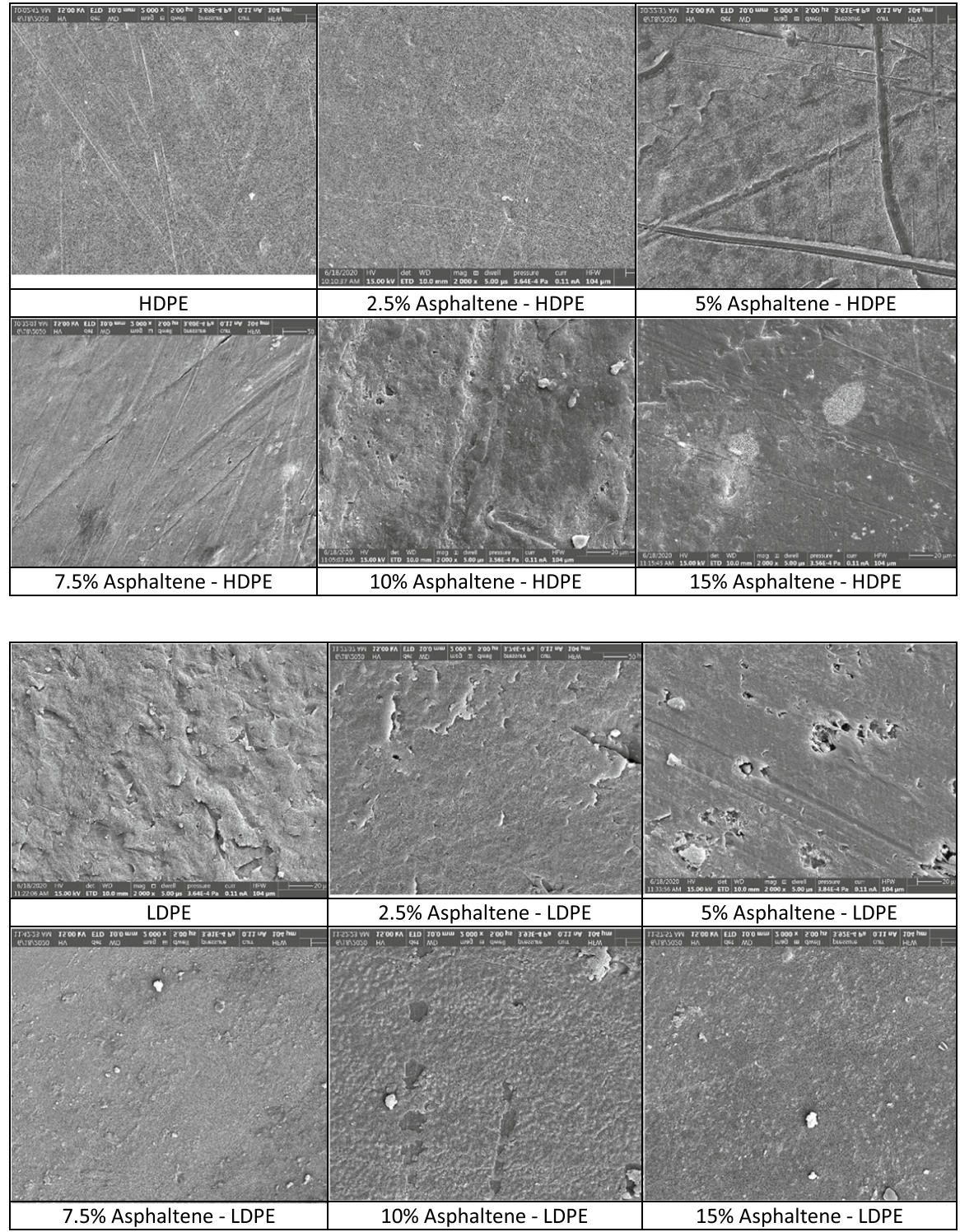

Fig. 3 SEM images of HDPE/LDPE polymers-asphaltene composites

Publisher's Note Springer Nature remains neutral with regard to jurisdictional claims in published maps and institutional affiliations. 